\title{
PROTECTIVE FACTORS AND TEACHERS' RISK TO BURN- OUT DURING THE COVID-19 PANDEMIC. DO KOLB'S ED- UCATOR ROLES MATTER? - A CLUSTER ANALYSIS
}

\author{
Camelia-Mădălina Răducu ${ }^{1}$ and Elena Stănculescu ${ }^{1}$ \\ 1 Faculty of Psychology and Educational Sciences; University of Bucharest; 90 Panduri Street, $5^{\text {th }}$ District, \\ 030018 Bucharest, Romania \\ * Correspondence: camelia.madalina.raducu.unibuc@gmail.com (C. -M.R.) \\ elena.stanculescu@fpse.unibuc.ro (E.S.)
}

\begin{abstract}
Teacher burnout has been revealed to be one of the most common negative consequence of the COVID-19 pandemic The purpose of this study was to identify distinct psychological resources and burnout risk profiles of teachers and to examine their association with Kolb's Educator Roles and the professional experience. Methods: The survey data were collected from 330 preschool and primary school ( 84 males, $M_{a g e}=38.3, S D=9.14$ ) teachers using a convenience sampling method. Results: The two-step cluster analysis revealed two distinct profiles. The first profile, 'High psychological resources, no burnout risk', was characterised by absent symptoms of burnout and increased levels of well-being, self-control, and positive emotionality. The second profile, 'Moderate psychological resources, mild burnout', was associated with medium levels of well-being, self-control and positive emotionality accompanied by mild burnout. Our findings highlighted that cluster 1 had a significantly higher score for the Facilitator role and cluster 2 for the Expert and Coach roles. In addition, teachers with less professional experience were more likely to belong to cluster 1, taking into account their good skills on digital literacy. Conclusions: These findings help to provide new insights into the explanation of teacher burnout and the design of intervention programmes.
\end{abstract}

Keywords: teacher burnout, well-being, self-control, positive emotionality, professional experience, psychological profile, COVID-19

\section{Introduction}

The last two school years have been extremely challenging for most teachers. In addition to the unprecedented situation generated by the coronavirus pandemic, COVID19, which led to the total closure of schools in March 2020, teachers subsequently experienced other new changes in the organisation of the instructional-educational process during the 2020-2021 school year. Specifically, they were forced to adapt in a short time to different teaching approaches, such as social distancing classes, hybrid teaching and virtual instruction, and to juggle between them depending on government policies and the rate of infections.

The new demands added to teachers' already full workloads, which even before COVID-19 were affected by burnout, anxiety and increased depression [1-3], symptoms that lead to frustration, dissatisfaction with teaching, job absenteeism and low selfefficacy [4-6]. 


\section{Theoretical background}

\subsection{Teachers' work-related burnout}

Teacher burnout was first conceptualised by Maslach and her colleagues [7] as a tripartite model of three progressive stages of burnout. The first stage, exhaustion, is described as emotional and physical fatigue resulting from having too many demands and not enough resources to meet them. The next stage, cynicism, is characterised by an increase in apathy, decrease in empathy and feelings of resentment or blame for others in the educational endeavour, including administrators, parents, and students. The final stage of burnout is a lack of accomplishment, where teachers perceive that the job is impossible and no longer believe they can teach successfully. In addition, the sociocontextual burnout [8] highlights that the professional community and teacher-pupil interactions are the primary arenas of teacher burnout, particularly in terms of perceived inadequacy and cynicism.

In the general context of the impoverishment of the teaching occupation [1], the pandemic crisis negatively affected teachers' psychological resources with new stressors proximal to burnout, such as fear of COVID-19 $[9,10]$, anxiety about teaching demands, parent communication and administrative support [10]. The lack of resources also affected teachers' accomplishments, demonstrating that the greater the perception of a resource deficit, the lower teachers perceive their accomplishments [11]. Moreover, the coronavirus pandemic had a clear impact on social relationships at all levels, increasing the socio-contextual burnout reported among teachers [12,13].

Thus, it is critical to help teachers face this difficulty by identifying the protective factors that help safeguard them and that promote optimal adaptability and resilience during stressful times at work [14,15]. Identifying the profiles of teachers who thrive in online teaching settings could contribute to improving psychosocial support [16] and teachers' work lives [17-19]. In addition, preventing burnout increases teachers' selfefficacy, job satisfaction, engagement and well-being [1,6,20-25].

Moreover, preventing teacher burnout not only improves teachers' personal and professional lives but also improves the online behaviour of students [26-28], creates a stable learning environment [29,30] and stimulates students' motivation and learning [31-34].

\subsection{Individual traits in preventing teacher burnout}

The most common individual traits discussed in the literature are emotional intelligence (EI). Trait EI is defined as a set of emotion-related self-perceptions and dispositions located at the lower levels of personality hierarchies and described under four dimensions: well-being, self-control, positive emotionality and sociability [35].

In the educational field, there is a mounting body of evidence lending support to the key role of EI competency and teachers' organisational commitment, job satisfaction, performance, self-efficacy, self-esteem, well-being and health indicators [36-44]. EI also decreases occupational stress and prevents burnout symptoms and negative feelings [45-51]. Similarly, for the teacher-student relationship, several studies have revealed that EI is crucial for supporting students' academic and social development [36,52-54].

The emotional resources were also related to personality traits and burnout. For instance, Pishghadam and Sahebjam's [55] study has revealed a significant relationship between personality types, EI and the three dimensions of burnout. It was indicated that the best predictors for emotional exhaustion are neuroticism and extroversion, the intrapersonal scale of EI and agreeableness for cynicism and the interpersonal scale of EI and conscientiousness for personal accomplishment.

2.3. Work-related traits in preventing teacher burnout

Concerning work-related traits, we consider the teaching style and the professional experience to be the most relevant for the present study because they have been mentioned in the literature as essential in profiling teachers [56-59]. 
Although there is a small body of research that investigates the link between teaching style and burnout, few studies have highlighted that teachers who guide and direct students by asking questions, exploring options and suggesting alternatives (Facilitator style) are the least likely to experience burnout [60-62]. Regarding profiling teaching styles, in his theory of experiential learning (ELT), Kolb [57] proposed a framework, The Educator Role Profile (ERP), that describes four different types of educators who respectively teach using four teaching styles: the Facilitator, who helps learners get in touch with their personal experience and reflect on it; the Expert, who helps learners organise and connect their reflections to the knowledge base of the subject matter; the Evaluator, who adopts an objective results-oriented style; and the Coach, who helps learners apply knowledge to achieve their goals. This framework was used in the present research to obtain information concerning the link between teaching style and burnout.

The literature also identifies professional experience as a major factor in preventing burnout. In this regard, despite the fact that previous studies have shown that teachers with more professional experience are less vulnerable to burnout $[12,13,63]$, the pressure of moving the whole instructional process to a remote environment concomitant to learning in a very short time with the use of new technologies increased the levels of stress and anxiety [64-66] and generated exhaustion and burnout even in the case of experienced teachers $[9,67]$. Moreover, the few studies conducted in the pandemic context revealed that older teachers often demonstrated weak digital skills, highlighting the need for professional development in using digital technologies [68], while the younger teachers used a higher number of tools for teaching and learning, demonstrated better digital competence and had more confidence in using digital technology and openness to new technology [69].

Recently, there has been an increased interest in individual variations of teacher burnout in terms of identifying teacher burnout profiles [13,70]. Burnout has been clustered with protective factors, such as well-being, work engagement, resilience and coping strategies, self-efficacy and collaboration within the community [13,63,71-73]. Still, the results on teacher prevention burnout profiles and factors contributing to the individual variations are insufficient. Depending on their profiles, teachers may engage different personal capacities and may utilise different strategies to relieve stressors. In this regard, extending the small body of literature that examines the individual variations and their determinants in preventing teacher burnout is required.

The purpose of this study was to identify distinct psychological resources and burnout risk profiles in preschool and primary school teachers and to examine their relationships with Kolb's Educator Roles and professional experience. The purpose of this analysis was to identify homogeneous groups or clusters based on their common characteristics. Considering previous studies on the relationship between well-being and teacher burnout $[42,71,74,75]$, we developed the first question: Are there distinct teacher profiles based on psychological resources, that is, well-being, self-control, positive emotionality, respectively burnout risk, during the COVID-19 pandemic? (RQ1). Based on the well-established association with professional experience $[18,63,72]$ and burnout, we developed the second question: Is there a positive association between profile membership and sociodemographic variables? (RQ2). Lastly, as previous studies have linked burnout to the teaching style [60-62], we developed the third question: Is there a positive association between profile membership and Kolb's Educator Roles? (RQ3).

\section{Methods}

\subsection{Participants}

The sample of this research was composed of 330 teachers $(\mathrm{N}=108$ preschool teachers, $N=222$ primary school teachers, $75 \%$ women, $M_{a g e}=38.3$ years, $\left.S D=9.14\right)$. Their reported professional experience was less than one year $(4.5 \%)$, between two and five years (10.9\%), between five and 10 years (19.1\%), between 10 and 20 years (25.5\%) and 
more than 20 years (40\%). A convenience sampling method was used. The sample was selected from the teacher register hold by Ilfov School Inspectorate via an e-mail paper survey sent to teachers. The total response rate was $45 \%$ from registered teachers.

\subsection{Procedure}

Before completing the survey, all the teachers were fully informed of the study's details and guaranteed confidentiality of all data obtained. The survey was comprised of two sections. The first section referred to participants' sociodemographic information, such as gender, teaching grades, years of professional experience and urban or rural teaching environment. The second section involved reporting the levels of burnout, well-being, self-control, positive emotionality, and the preference for a certain type of teaching role. The study was conducted in accordance with the Declaration of Helsinki and the recommendations and approval of the University of Bucharest Ethics Committee. Data were collected via Google Forms during spring 2021. The link to the online survey was posted with a short description of its purpose, the length of time needed to complete. In exchange for completing the questionnaires, certificates of participation in the research were provided for the teacher's personal file. The selection criteria for inclusion in this study were a primary or preschool level of teaching. All participants were voluntarily involved and gave their written informed consent prior to completing the questionnaire.

\subsection{Measures}

Teacher burnout. Given the pandemic context, the Socio-Contextual Teacher Burnout Inventory (STBI)[8] has been used for measuring teacher burnout. This nine-item (e.g., 'With this work pace, I don't think I'll make it to the retiring age') scale was evaluated based on a Likert scale from 1 - completely disagree to 7 - completely agree. The established three constructs were teacher exhaustion, cynicism towards the teacher community and inadequacy in the pupil-teacher relationship. The Cronbach's alpha for the entire scale was .90 (95\% CI $[.89, .91])$, and for its dimensions: exhaustion - .84 (95\% CI, $[.93, .95])$, cynicism - - .85 (95\% CI $[.84, .97])$ and inadequacy - .84 (95 \% CI, [.93, .95]).

Well-being. Teachers' well-being was measured with the well-being subscale from the Trait Emotional Intelligence Questionnaire-Short Form for Adults (TEIQue - ASF) [76]. This scale consists of 30 items evaluated on a Likert scale from 1 - completely disagree to 7 - completely agree, whose items (e.g., 'I generally don't find life enjoyable.') measure emotional intelligence under four aspects: well-being, self-control, emotionality, and sociability. For the present research, the .90 Cronbach's $\alpha$ indicated a high internal consistency $(95 \% \mathrm{CI},[.88, .91])$. The Cronbach's $\alpha$ for the well-being subscale was. $80(95 \% \mathrm{CI},[.75, .85])$.

Self-control. Teachers' self-control was measured using the self-control subscale from the TEIQue - ASF [76]. This subscale is composed of six items (e.g., 'I usually find it difficult to regulate my emotions.') The Cronbach's $\alpha$ for the well-being subscale was .83 (95\% CI, [.82, .85]).

Positive emotionality. Teachers' positive emotionality was measured by the emotionality subscale from the TEIQue - ASF [76]. This subscale contains eight items (e.g., 'Expressing my emotions with words is not a problem for me.'). The Cronbach's $\alpha$ for the emotionality scale was .94 (95\% CI, $[.93, .95])$

The Educator Roles. We represented the pedagogical and content related aspects of teaching style focusing on Kolb's Educator Role Profile (KERP) [56]. KERP is a selfassessment tool that includes items related to individual teaching style, beliefs about teaching and learning, goals for the educational process and instructional practices [56]. KERP includes 30 items that are forced-choice types of four educator roles: Facilitator (e.g., I aim for learners to develop a lifelong love of learning), Expert in the Subject Matter (e.g., I share my subject matter knowledge and expertise), Evaluator/Standard Setter (e.g., I use tests to evaluate learners' understanding of a subject) and Coach (e.g., I believe learning occurs best in a real-life context). The Cronbach's $\alpha$ for the entire scale was 
0.76 at a $95 \% \mathrm{CI}$, and for the subscales, it was as follows: Facilitator .83 (95\% CI, [.82, $.85])$, Expert .63, (95\% CI, [.62, .65]), Evaluator .57 (95\% CI, [.56, .59]) and Coach .72 (95\% CI, $[.71,74])$.

\subsection{Statistical Analysis}

A two-step cluster analysis with the Euclidean measure and the Akaike Information Criterion (AIC) was used to explore possible profiles in our sample. This technique has advantages compared to more traditional clustering procedures [77] because it determines the number of clusters based on statistical measures of fit (AIC or BIC, Average Silhouette - indicator of cohesion and separation - and ratio of sizes - largest cluster to smallest cluster) and analyses atypical values (i.e. outliers). The model selection criteria followed the principle of parsimony, where the best cluster solution is the one with the lowest value of the AIC, a good level fit (cutoff $>0.5$ ) highlighted by the Average Silhouette coefficient and a cutoff $<2$ in the case of ratio of sizes, as recommended by Kent et al. [77]. Using the best cluster solution allows for the measurement of the improvement of homogeneity within each cluster and the heterogeneity between the clusters from one cluster to $n+1$ cluster by adding one cluster at each step. Various one-way ANOVAs tests were performed to verify the differences in the clusters' indicators between the distinct profiles, the association between profile membership and Kolb's educator roles. In addition, a multinomial logistic regression was computed to calculate the predictive roles of the sociodemographic variables, including gender, education level, urban/rural education, and professional experience, on profile membership.

\section{Results}

\subsection{Step 1: Preliminary analysis - descriptive statistics and correlations}

The descriptive statistics for demographic characteristics, depending on the level of burnout are shown in Table 1 . The means, SD, univariate normality coefficients and correlation matrix are presented in Table 2.

Table 1. Sociodemographic variables - descriptive statistics depending on burnout risk

\begin{tabular}{ccccc}
\hline \multirow{2}{*}{$\begin{array}{c}\text { Sociodemographic } \\
\text { variables }\end{array}$} & & \multicolumn{2}{c}{ Burnout risk } & \multirow{2}{*}{ Total } \\
\cline { 2 - 4 } & & No risk & Moderate level & \\
\hline \multirow{2}{*}{ Gender } & Male & 139 & 107 & 246 \\
\cline { 2 - 5 } & Female & 44 & 40 & 84 \\
\hline Teaching level & Preschool & 60 & 48 & 108 \\
\cline { 2 - 5 } & Primary & 123 & 99 & 122 \\
\hline \multirow{2}{*}{ Place } & Urban & 124 & 93 & 217 \\
\cline { 2 - 5 } & Rural & 59 & 54 & 113 \\
\hline Professional experience & $<2$ & 12 & 3 & 15 \\
\cline { 2 - 5 } (years) & $2-5$ & 30 & 6 & 36 \\
\cline { 2 - 5 } & $6-10$ & 48 & 15 & 63 \\
\cline { 2 - 5 } & $11-20$ & 30 & 54 & 84 \\
\cline { 2 - 5 } & $>20$ & 63 & 69 & 132 \\
\hline
\end{tabular}

Prior to conducting the two-step cluster analysis, two assumptions were verified. The first assumption regarding the independence of the variables included in the cluster model was satisfied (as shown in Table 2) taking into account the cutoff criterion ( $\mathrm{r}<$ .70), as suggested by Nunnally [78]. The second assumption related to the univariate normality of all the profiles' indicators was also met. As can be seen in Table 2, the cutoff criteria recommended in the literature (skewness $<2$; kurtosis $<7$ ) by West et al. [79] were not exceeded. 
Table 2. Means, $S D$, univariate normality coefficients, and correlation matrix

\begin{tabular}{cccccccc}
\hline Clusters' indicators & Mean (SD) & $\begin{array}{c}\text { Skewness } \\
\text { (Std. Err) }\end{array}$ & $\begin{array}{c}\text { Kurtosis } \\
\text { (Std. Err) }\end{array}$ & 1 & 2 & 3 & 4 \\
\hline Well-being & $5.44(0.95)$ & $-0.04(134)$ & $-1.10(268)$ & - & & \\
Self-control & $4.70(0.87)$ & $0.64(134)$ & $-0.01(268)$ & $.42^{* *}$ & - & \\
Positive emotionality & $4.74(0.99)$ & $0.08(134)$ & $-0.72(268)$ & $.59^{* *}$ & $.43^{* *}$ & - & \\
Burnout & $33.65(13.53)$ & $-0.03(134)$ & $-1.01(268)$ & $.52^{* *}$ & $.50^{* *}$ & $.53^{* *}$ & - \\
\hline${ }^{* *} p<0.01$. & & & & & & &
\end{tabular}

\subsection{Step 2: Cluster analysis (RQ1)}

Identifying the number of profiles

Inspecting the graph of AIC created by auto-clustering (see Figure 1), we found multiple solutions ranging from two to four clusters. We tried to minimise the AIC but not at the cost of the other fit index, which is the measure of cohesion and separation (Average Silhouette coefficient).

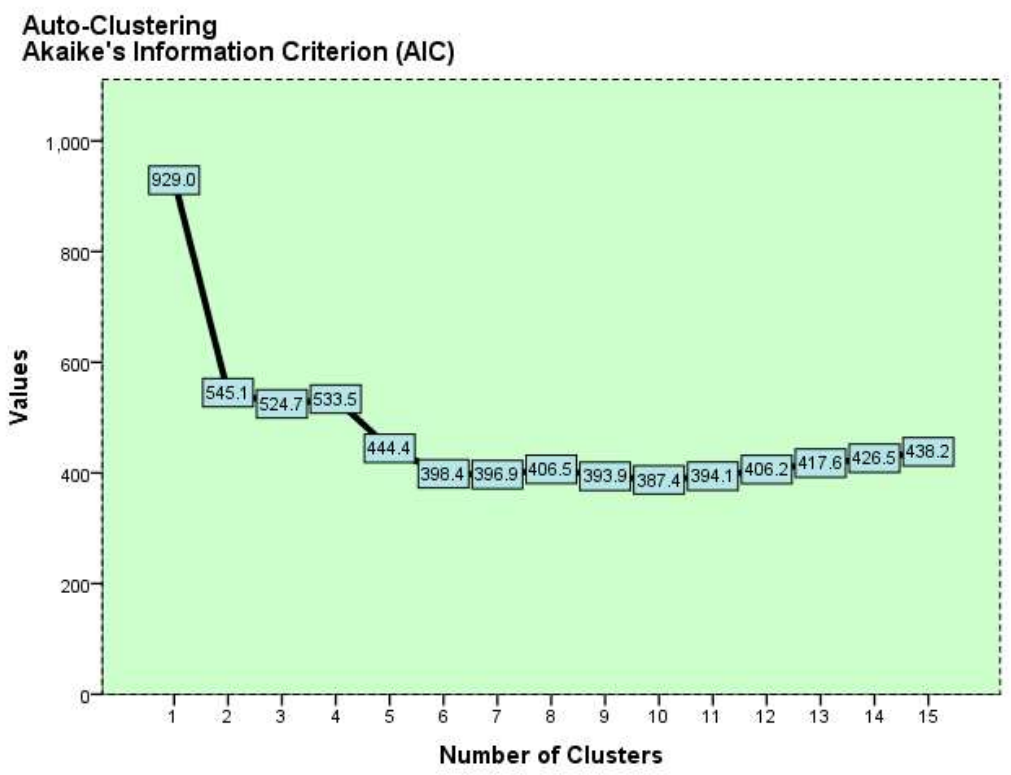

Figure 1. Auto-clustering - Akaike's Information Criterion (AIC)

The best solution was the model with 2 clusters. As highlighted in Table 3, as the number of clusters increased, it is observed that in each step, although the value of AIC decreased, there was a decrease of the fit criteria model, i.e., the decrease of the Silhouette coefficient as well as the ratio sizes.

Table 3. Model fit information - goodness of fit indicators

\begin{tabular}{cccc}
\hline Number of clusters & Average Silhouette & $\begin{array}{c}\text { Akaike's Information Criterion } \\
\text { (AIC) }\end{array}$ & Ratio of sizes \\
\hline 2 & 0.5 & 545.1 & 1.52 \\
3 & 0.4 & 524.7 & 4.75 \\
4 & 0.4 & 533.5 & 11.40 \\
\hline
\end{tabular}


Characteristics of the identified profiles

The first cluster ( $\mathrm{n}=199 ; 60.3 \%$ ) from our analysis was the 'High psychological resources, no burnout risk' profile. It includes teachers with higher scores on well-being, self-control and positive emotionality accompanied by the lowest scores on burnout, which means no burnout risk (see Table 3 ). The second cluster $(\mathrm{n}=131 ; 39.7 \%)$ was the 'Moderate psychological resources, mild burnout risk' profile. Teachers belonging to this profile had medium scores on well-being, self-control and positive emotionality combined with a mild risk to develop burnout.

Table 4. Means and SD of profiles' indicators across two clusters

\begin{tabular}{ccc}
\hline Profiles' indicators & Cluster 1 & Cluster 2 \\
\cline { 2 - 3 } & $\begin{array}{c}\text { High psychological resources, } \\
\text { no burnout risk }\end{array}$ & $\begin{array}{c}\text { Moderate psychological resources } \\
\text { and mild burnout risk }\end{array}$ \\
\hline Well-being & $6.28(0.57)$ & $4.90(0.73)$ \\
Self-control & $5.50(0.72)$ & $4.19(0.49)$ \\
Positive emotionality & $5.61(0.67)$ & $4.18(0.73)$ \\
Burnout & $21.23(8.57)$ & $41.61(9.53)$ \\
\hline
\end{tabular}

Various one-way ANOVAs were conducted to examine the differences in the level of clusters' indicators between the two profiles. The results revealed significant differences for all indicators. In the first cluster, higher scores emerged for: (i) well-being $($ Welch F $(1,315.569)=369.148 ; p<.001)$; (ii) self-control $($ Welch F $(1,203.969)=327.813 ; p$ $<.001$ ); (iii) positive emotionality (Welch F $(1,290.987)=331.206$; $\mathrm{p}<.001)$; and lower score for teacher burnout (Welch F $(1,293.652)=406.369 ; p<.001)$.

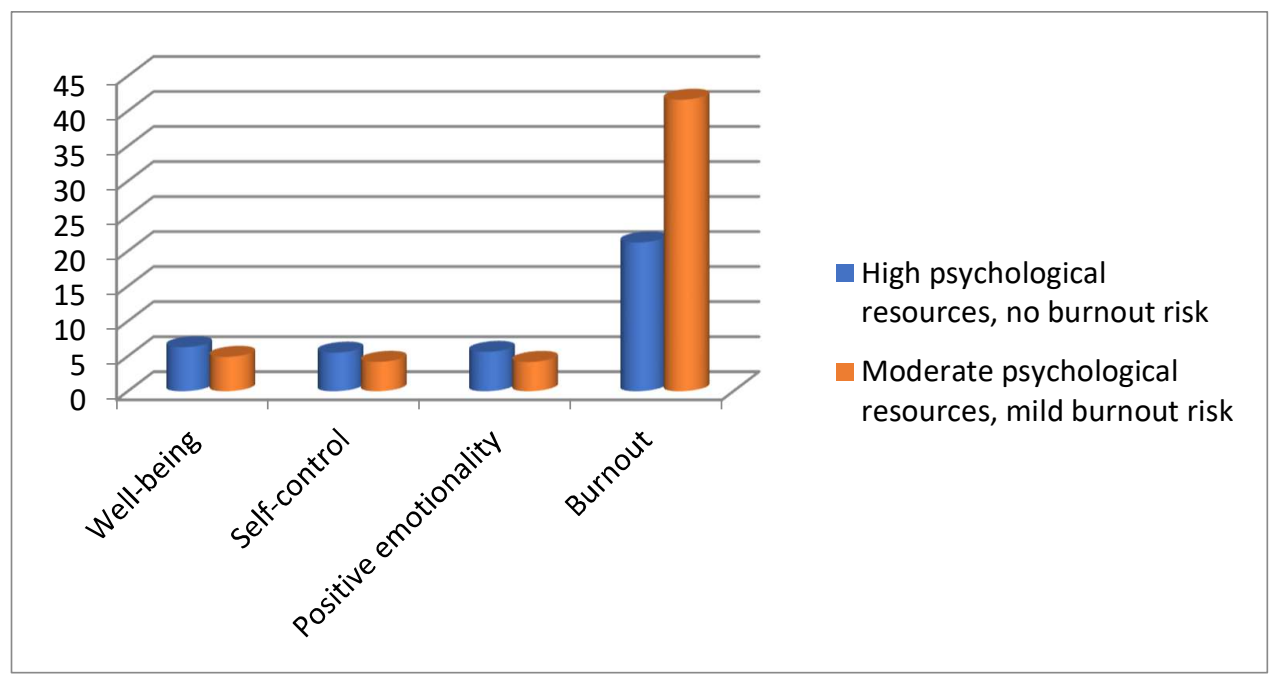

Figure 3. Profiles' indicators (means) across two clusters

\subsection{Step 3: Cluster analysis and teacher variables}

Association between profile membership and sociodemographic variables (RQ2)

The association between profile membership and sociodemographic variables, including gender, teaching level, urban/rural education, and professional experience, was examined using the multinomial logistic regression. The results showed that gender $(b=$ $.07, S E=.276$, Wald $=.07, p=.791)$, teaching level $(\mathrm{b}=.27, S E=.261$, Wald $=1.11, \mathrm{p}=.296)$ and urban-rural education $(b=.17, S E=.249$, Wald $=.49, p=.482)$ were not significant predictors in the model. Instead, professional experience had a significant predictive role $(b=.41, S E=.10$, Wald $=17.09, p<.001 ; O R=1.51,95 \% \mathrm{CI}(1.24,1.89)$. Overall, the results 
showed the following patterns. Men and women were not predominantly represented in one of the two profiles. In other words, no gender differences were obtained in terms of distribution in the two clusters. The same pattern was found for teachers in rural or urban education. Even in the case of those working in preschool and primary education, no statistically significant differences were observed within the two profiles. However, in the case of professional experience, our findings showed that those with less experience (less than one year and up to ten years), i.e., the youngest and most familiar with the digital environment, were less likely to belong to the mild profile and more likely to belong to the high mental health profile (as shown in Figure 3). An opposite pattern in the case of teachers with the highest levels of experience was found. They were more likely to belong to the 'Moderate psychological resources and mild burnout' risk profile and less likely to belong to the other.

Association between profile membership and Kolb's educator roles (RQ3)

The results obtained from various one-way ANOVAs provided evidence for a significant association between profiles and Kolb's educator roles, i.e. (i) facilitator role $[\mathrm{F}(1,328)=120.347 ; p<.001]$, (ii) expert role $[\mathrm{F}(1,328)=80.921 ; p<.001]$, and (iii) coach role $[\mathrm{F}(1,328)=10.291 ; p<.001]$, except for the evaluator role $[\mathrm{F}(1,328)=2.911 ; p=.089]$. Cluster 1 had a significantly higher number for the facilitator role $(M=8.67, S D=1.786)$ than Cluster $2(M=6.01, S D=2.358)$. In contrast, Cluster 2 had a significantly higher number for the expert role $(M=8.92, S D=2.782)$ than Cluster $1(M=6.12, S D=2.701)$. The same pattern was highlighted for the coach role-a higher number for Cluster $2(M$ $=9.04, S D=3.255)$ than Cluster $1(M=7.90, S D=3.021)$. As mentioned, for the evaluator role, no significant differences were found (cluster $1-M=7.09, S D=2.376$; cluster $2-M$ $=6.57, S D=2.898$ ).

\section{Discussion}

In the coronavirus pandemic context, teacher burnout has become a global epidemic [56] and a major concern in the educational debate both for practitioners and professionals and for psychologists and experts in educational policy. The main aim of this research was to identify protective factors and teachers' risk of burnout profiles in the framework of Kolb's Experiential Learning Theory [56]. We also explored associations between profile membership and sociodemographic variables on the one hand and Kolb's educator roles on the other. The two-step cluster analysis revealed two different profiles.

The 'High psychological resources, no burnout risk' included teachers with higher scores on well-being, self-control positive emotionality and no burnout risk. In this regard, teachers who perceive and express emotions, show empathy, build good relationships, and master their emotions, impulsiveness and stressful feelings are more protected against burnout symptoms. Their increased levels of self-esteem, happiness and optimism are also beneficial resources that help them manage stressors [35]. Our results are in line with previous research that highlighted the relationship between well-being and burnout [27,49,61,63,71]. More specifically, the cluster of 'High psychological resources, no burnout risk' included teachers who showed very low scores on burnout scale, meaning, in fact, no risk of burnout. They found resources to protect themselves in the adverse context for which no one was prepared. Their dispositional traits, meaning selfcontrol and positive emotionality, along with well-being contributed to the buffering of the negative impact of stressors.

The 'Moderate psychological resources, mild burnout risk' included teachers with medium scores on well-being, self-control, positive emotionality, and mild burnout risk. In this regard, teachers who are less skillful in perceiving and expressing emotions, showing empathy, building good relationships and mastering their emotions, impulsiveness and stressful feelings are more likely to experience burnout symptoms $[50,55,61]$. Their low levels of self-esteem, happiness and increased pessimism makes 
them far more vulnerable to work-related stressors. Even if 'Moderate psychological resources, mild burnout risk' teachers reported symptoms of burnout, feeling exhaustion, cynicism towards the teacher community and inadequacy in the pupil-teacher relationship, this does not mean that they fulfil the clinical criteria of being burned out but that they do have an increased risk of developing it.

These findings are in line with previous studies that have shown emotional resources as strong predictors of teacher burnout [45-47,50,55]; however, the results expand the previous research on teacher burnout by showing more refined sociocontextualized differences in teacher prevention burnout profiles in terms of well-being, self-control and positive emotionality.

The results imply that there is a variation in teaching roles and professional experience among teachers: some of the teachers seem to prefer certain teaching roles that are less burdensome. In this regard, the results showed that the teacher protective burnout profiles differed from each other primarily in terms of preferred teaching role. The teachers who are characterised by a Facilitator role are more likely to be assigned to the 'High psychological resources, no burnout risk' profile. A reason for this alignment may be that the Facilitator teaching style has been proven to produce the highest average values for students' online exams [80]. On the other hand, our findings emphasise that the teachers included in the second cluster, i.e., 'Moderate psychological resources, mild burnout risk', had a higher score on Expert and Coach educator roles. Despite the fact that the Coach teaching role was previously proven to be the most appropriate style in one-on-one teaching for students with the lowest mean grades in the pandemic context [80], the possibilities of practice in online learning classrooms are highly restrained. Second, concerning the Expert role, our results are in line with previous studies that revealed that this role is the least engaging and inaccessible in students' opinions related to online teaching [81]; so it is expected that the Experts would feel more stress due to the difficulty to cap and maintain students' attention. In this regard, the present research has enriched the gap in literature concerning the link between teaching roles as a protective factor against burnout, showing that the Facilitator teaching style that helps learners get in touch with their personal experience and reflect on it is the least stressful for online teaching, while the Experts and Coaches are more stressed regarding online teaching. This may be because the Expert's purpose is to help learners organise and connect their reflections to the knowledge base of the subject matter through lectures and texts in an reflective-authoritative style [56], and these strategies may be less interesting and engaging for students. Second, the Coach's interest is helping learners apply knowledge to achieve their goals [56], but this style-as is described in ELT-is more appropriate for one-on-one learning, and in a remote environment, this strategy is almost impossible to use with every student. The Evaluator teaching style was quite equally represented in both profiles. Within Kolb's theory framework, this role involves setting standards of performance and structuring performance activities. Evaluator teacher role involves the use of tests, assessments, and projects but no being created a personal relationship with the student because the teacher focuses on the subject and on the evaluation. Thus, despite the fact that the Evaluator role has been previously proven to facilitate online learning among students from higher education [80], it seems that in preschool and primary school education, it is required that the learning be more concrete, more practical and instructional and less often evaluated through tests and assignments.

In addition, our overall results showed a significant association between profile membership and professional experience. Teachers with less professional experience were more likely to belong to the 'High psychological resources, no burnout risk' profile, and members of the profile 'Moderate psychological resources, mild burnout risk' were more likely to be experienced teachers. This may seem to contradict previous studies [13] that related high levels of professional experience to a low risk of burnout; however, taking into account that the pandemic context created new stressors, such as tech- 
nostress and a lack of resources and administrative support [9,65], the situation seems to have changed. Consequently, these results may be in line with the latest studies that suggested that experienced and self-confident teachers in face-to-face teaching became suddenly deskilled when transitioning to online teaching, experiencing disempowerment, vulnerability and frustration in using remote technology $[72,82,83]$. At the same time, openness to new technology, confidence and increased digital competences [69] could protect younger teachers from burnout symptoms.

Our study contributes to expanding the empirical body of research on teacher burnout $[12,73,83]$ by being one of the first studies to explore the teachers' individual traits in terms of personal resources and burnout risk profiles within the framework of Kolb's Experiential Learning Theory [56]. The results showed that the teachers' wellbeing, self-control, and positive emotionality help them in buffering work-related stressors in online teaching in the COVID-19 pandemic context. Moreover, the higher these internal resources were, the lower the risk of experiencing burnout. This highlights that the emotional resources represent a strong internal barrier against imminent stressors and that preparing functional psychological strategies can prevent burnout syndrome. Our results also indicated that the preferred teaching roles and professional experience are related to the burnout risk. While the most protective style against burnout is the Facilitator role, the Expert and Coach roles were associated with a mild burnout risk profile. In addition, the fewer years of teaching experience a teacher had, the lower the burnout risk in an online teaching context. Accordingly, the most protected teachers in the pandemic context are the Facilitators with high levels of well-being, self-control, and positive emotionality, while the most at-risk teachers are those who prefer the Expert and Coach roles and moderate levels of well-being, self-control, and positive emotionality. Another contribution is that our study is based on a person-centered approach, meaning the two-step cluster analysis. In fact, we proved not simply associations between research variables but also found distinct teachers' profiles and their predictors in terms of professional experience and Kolb's educator roles.

Moreover, in contrast with previous studies who investigated teachers' burnout profile only from the health psychology angle [13,63,71,72], our study brings in addition also constructs from educational sphere reuniting two different perspectives into an new point of view on teacher's burnout.

Thus, this study has two main educational implications. First, this study emphasizes the teachers' need for professional and personal development of emotional competencies to help them manage stress in the classroom both in normal educational contexts and in adverse social and health conditions contexts. Second, the theoretical framework of the ELT encourages teachers to move away from the consistent Expert teaching role, where the teacher imposes an objective results-oriented approach on young learners, and Coach teaching role where teacher works one-to-one to apply the learning concepts, to the Facilitator teaching role. This role uses a worm-affirmative style, promote an "inside-out" learning to draw out motivation and self-knowledge and creates personal relationships and dialogue

Regarding the limitations of this study, it is important to note that a correlational design has been employed, which limits our ability to infer causal links. In addition, the present findings cannot be generalised due to the convenience sampling method used. Considering that most of the respondents were women, they were slightly overrepresented in the sample. There are recommendations for future study directions. Longitudinal designs are necessary to capture the possible developmental trajectories of burnout in line with the theoretical assumption underlying protective factors, such as dispositional traits and coping strategies in the context of technostress, and covariates, such as educator roles and digital literacy skills. 


\section{Conclusions}

In summary, the new demands on the current education system caused teachers to juggle three different types of teaching approaches: social distancing in classes, online teaching, and hybrid teaching. In this context, short- and long-term impacts of the COVID-19 pandemic on preschool and primary education have led to increased levels of burnout among teachers $[9,11]$. This study has shown that the teachers who are less protected against the burnout profile during the adverse context of the COVID-19 pandemic are those with moderate levels of well-being, self-control, and positive emotionality and who prefer the Expert and Coach educator roles. In contrast, the most protected against burnout are those who have high levels of well-being, self-control and positive emotionality along with the advantages of the Facilitator role in interacting with students. Firstly, the results can be useful for teacher' training specialists to promote programs that help teachers to cope with stressors in online teaching, regulate their emotional resources, and how to use effective and less consuming teaching strategies such as those specific to the Facilitator Role. The need to improve teachers' digital skills must also be considered to facilitate and streamline their work. Secondly, as it is necessary for all organizations to promote the health of their employees, also in the case of teachers it tremendous important that educational managers support teacher's health and well-being by creating good working conditions and by developing programs to equip teachers with the emotional competency and coping strategies necessary both in normal educational contexts and in adverse social and health conditions as are those of the COVID-19 pandemic.

Author Contributions: Conceptualization, C.M.-R and E.-S., C.M.-R. developed the questionnaires and collected the data. E.-S. and C.M.-R. developed the analytical plan and undertook the statistical analyses. C.M.-R, E.S. interpreted the results of the statistical analyses. E.-S. and C.M.-R wrote the paper. All authors have read and agreed to the published version of the manuscript.

Funding: This research received no external funding.

Institutional Review Board Statement: The study was conducted according to the guidelines of the Declaration of Helsinki and approved by the University of Bucharest Ethics Committee (no 11/ 26.04.2021)

Informed Consent Statement: Informed consent was obtained from all subjects involved in the study.

Data Availability Statement: The data are available for those who want to see it with justified reasons. Kindly contact the corresponding author.

Conflicts of Interest: Authors declare no conflict of interest.

References

(1) Ferguson, K.; Frost, L.; Hall, D. Predicting Teacher Anxiety, Depression, and Job Satisfaction. J. Teach. Learn. 2012, 8 (1), 23-38.

(2) McLean, L.; Connor, C. M. Depressive Symptoms in Third-grade Teachers: Relations to Classroom Quality and Student Achievement. Child Dev. 2015, 86 (3), 945-954.

(3) Mahan, P. L.; Mahan, M. P.; Park, N.-J.; Shelton, C.; Brown, K. C.; Weaver, M. T. Work Environment Stressors, Social Support, Anxiety, and Depression among Secondary School Teachers. AAOHN J. 2010, 58 (5), 197-205.

(4) Arvidsson, I.; Leo, U.; Larsson, A.; Håkansson, C.; Persson, R.; Björk, J. Burnout among School Teachers: Quantitative and Qualitative Results from a Follow-up Study in Southern Sweden. BMC Public Health 2019, 19 (1), 1-13.

(5) Pellerone, M.; Rapisarda, V.; Trischitta, M. C. A.; Vitale, E.; Ramaci, T. Burnout and Self-Perceived Instructional Competence: An Exploratory Study of a Group of Italian Female Elementary School Teachers. Int. J. Environ. Res. Public. Health 2020, 17 (4), 1356.

(6) Capri, B.; Guler, M. Evaluation of Burnout Levels in Teachers Regarding Sociodemographic Variables, Job Satisfaction and General Self-Efficacy. Eurasian J. Educ. Res. 2018, 18 (74), 123-144.

(7) Maslach, C.; Jackson, S. E.; Leiter, M. P. Maslach Burnout Inventory; Scarecrow Education, 1997.

(8) Pietarinen, J.; Pyhältö, K.; Soini, T.; Salmela-Aro, K. Reducing Teacher Burnout: A Socio-Contextual Approach. Teach. Teach. Educ. 2013, 35, 62-72.

(9) Pressley, T. Factors Contributing to Teacher Burnout During COVID-19. Educ. Res. 2021, 50 (5), $325-327$. https://doi.org/10.3102/0013189X211004138. 
(10) Stănculescu, E. Fear of COVID-19 in Romania: Validation of the Romanian Version of the Fear of COVID-19 Scale Using Graded Response Model Analysis. Int. J. Ment. Health Addict. 2021, 1-16.

(11) Sokal, L. J.; Trudel, L. G. E.; Babb, J. C. Supporting Teachers in Times of Change: The Job Demands-Resources Model and Teacher Burnout during the COVID-19 Pandemic. Int. J. Cont. Educ. 2020, 45-56

(12) Pietarinen, J.; Pyhältö, K.; Haverinen, K.; Leskinen, E.; Soini, T. Is Individual-and School-Level Teacher Burnout Reduced by Proactive Strategies? Int. J. Sch. Educ. Psychol. 2021, 1-16.

(13) Pyhältö, K.; Pietarinen, J.; Haverinen, K.; Tikkanen, L.; Soini, T. Teacher Burnout Profiles and Proactive Strategies. Eur. J. Psychol. Educ. 2020, 1-24.

(14) Drew, S. V.; Sosnowski, C. Emerging Theory of Teacher Resilience: A Situational Analysis. Engl. Teach. Pract. Crit. 2019. 4-17.

(15) Ainsworth, S.; Oldfield, J. Quantifying Teacher Resilience: Context Matters. Teach. Teach. Educ. 2019, 82, $117-128$.

(16) McKenzie, J.; Olson, R. E.; Patulny, R.; Bellocchi, A.; Mills, K. A. Emotion Management and Solidarity in the Workplace: A Call for a New Research Agenda. Sociol. Rev. 2019, 67 (3), 672-688.

(17) Kumar, D.; Singh, D.; Parkash, P. Psychological Well-Being And Quality Of Worklife Of The School Teachers During The Covid-19 Situation. Eur. J. Mol. Clin. Med. 2021, 7 (7), 6309-6316.

(18) Vercambre, M.-N.; Brosselin, P.; Gilbert, F.; Nerriére, E.; Kovess-Masféty, V. Individual and Contextual Covariates of Burnout: A Cross-Sectional Nationwide Study of French Teachers. BMC Public Health 2009, 9 (1), 1-12.

(19) Farley, A. N.; Chamberlain, L. M. The Teachers Are Not Alright: A Call for Research and Policy on Teacher Stress and WellBeing. New Educ. 2021, 1-19.

(20) Fathi, J.; Saeedian, A. A Structural Model of Teacher Self-Efficacy, Resilience, and Burnout among Iranian EFL Teachers. Iran. J. Engl. Acad. Purp. 2020, 9 (2), 14-28.

(21) Hampton, D.; Culp-Roche, A.; Hensley, A.; Wilson, J.; Otts, J. A.; Thaxton-Wiggins, A.; Fruh, S.; Moser, D. K. Self-Efficacy and Satisfaction with Teaching in Online Courses. Nurse Educ. 2020, 45 (6), 302-306.

(22) Skapinaki, A.; Salamoura, M. Investigating Primary School Quality Using Teachers' Self-Efficacy and Satisfaction. Learn. Individ. Differ. 2020, 56-78. https://doi.org/10.5281/ZENODO.3603339.

(23) Perera, H. N.; Granziera, H.; Mcllveen, P. Profiles of Teacher Personality and Relations with Teacher Self-Efficacy, Work Engagement, and Job Satisfaction. Personal. Individ. Differ. 2018, 120, 171-178. https://doi.org/10.1016/j.paid.2017.08.034.

(24) Abós, Á.; Sevil-Serrano, J.; Haerens, L.; Aelterman, N.; García-González, L. Towards a More Refined Understanding of the Interplay between Burnout and Engagement among Secondary School Teachers: A Person-Centered Perspective. Learn. Individ. Differ. 2019, 72, 69-79.

(25) Christensen, M.; Dyrstad, J. M.; Innstrand, S. T. Academic Work Engagement, Resources and Productivity: Empirical Evidence with Policy Implications. Stud. High. Educ. 2020, 45 (1), 86-99.

(26) Sokal, L.; Trudel, L. E.; Babb, J. Canadian Teachers' Attitudes toward Change, Efficacy, and Burnout during the COVID-19 Pandemic. Int. J. Educ. Res. Open 2020, 1, 100016. https://doi.org/10.1016/j.ijedro.2020.100016.

(27) Bakioğlu, F.; Kiraz, Z. Burnout and Wellbeing of Teacher Candidates: The Mediator Role of Cynicism. An. Psicol. Psychol. 2019, 35 (3), 521-528.

(28) Meredith, C.; Schaufeli, W.; Struyve, C.; Vandecandelaere, M.; Gielen, S.; Kyndt, E. 'Burnout Contagion'among Teachers: A Social Network Approach. J. Occup. Organ. Psychol. 2020, 93 (2), 328-352.

(29) Grayson, J. L.; Alvarez, H. K. School Climate Factors Relating to Teacher Burnout: A Mediator Model. Teach. Teach. Educ. 2008, 24 (5), 1349-1363.

(30) Sönmez, S.; Betül Kolaşınlı, I. The Effect of Preschool Teachers' Stress States on Classroom Climate. Educ. 3-13 2021, 49 (2), 190-202.

(31) Shen, B.; McCaughtry, N.; Martin, J.; Garn, A.; Kulik, N.; Fahlman, M. The Relationship between Teacher Burnout and Student Motivation. Br. J. Educ. Psychol. 2015, 85 (4), 519-532.

(32) Zhang, Q.; Sapp, D. A. A Burning Issue in Teaching: The Impact of Perceived Teacher Burnout and Nonverbal Immediacy on Student Motivation and Affective Learning. J. Commun. Stud. 2008, 1 (2) 56-78.

(33) Yavuz, G.; Dogan, N. Maslach Burnout Inventory-Student Survey (MBI-SS): A Validity Study. Procedia-Soc. Behav. Sci. 2014, $116,2453-2457$.

(34) Hernesniemi, E.; Räty, H.; Kasanen, K.; Cheng, X.; Hong, J.; Kuittinen, M. Students' Achievement Motivation in Finnish and Chinese Higher Education and Its Relation to Perceived Teaching-learning Environments. Scand. J. Psychol. 2020, 61 (2), 204217.

(35) Petrides, K. V.; Furnham, A. Trait Emotional Intelligence: Psychometric Investigation with Reference to Established Trait Taxonomies. Eur. J. Personal. 2001, 15 (6), 425-448.

(36) Fabio, A. D.; Palazzeschi, L. Emotional intelligence and self-efficacy in a sample of italian high school teachers. Soc. Behav. Personal. Int. J. 2008, 36 (3), 315-326. https://doi.org/10.2224/sbp.2008.36.3.315.

(37) Anari, N. N. Teachers: Emotional Intelligence, Job Satisfaction, and Organizational Commitment. J. Workplace Learn. 2012, 4566

(38) Mohamad, M.; Jais, J. Emotional Intelligence and Job Performance: A Study among Malaysian Teachers. Procedia Econ. Finance 2016, 35, 674-682.

(39) Toprak, M.; Savaş, A. C. School Headmasters' Emotional Intelligence and Teachers' Job Satisfaction: Moderation Effect of Emotional Labor. New Horiz. Adult Educ. Hum. Resour. Dev. 2020, 32 (2), 4-18. 
(40) Penrose, A.; Perry, C.; Ball, I. Emotional Intelligence and Teacher Self Efficacy: The Contribution of Teacher Status and Length of Experience. Issues Educ. Res. 2007, 17 (1), 107-126.

(41) Sahin, H. Emotional Intelligence and Self-Esteem as Predictors of Teacher Self-Efficacy. Educ. Res. Rev. 2017, 12 (22), 11071111.

(42) Vesely, A. K.; Saklofske, D. H.; Leschied, A. D. Teachers-The Vital Resource: The Contribution of Emotional Intelligence to Teacher Efficacy and Well-Being. Can. J. Sch. Psychol. 2013, 28 (1), 71-89.

(43) González-Valero, G.; Zurita-Ortega, F.; Chacón-Cuberos, R.; Puertas-Molero, P. Analysis of Motivational Climate, Emotional Intelligence, and Healthy Habits in Physical Education Teachers of the Future Using Structural Equations. Sustainability 2019, $11(13), 3740$.

(44) Stănculescu, E. Psychological Predictors and Mediators of Subjective Well-Being in a Sample of Romanian Teachers. Rev. Cercet. Şi Interv. Socială 2014, No. 46, 37-52.

(45) John, F. D. B. A STUDY ON EMOTIONAL INTELLIGENCE AND TEACHERS'STRESSES IN COVID SITUATION. Ann. Romanian Soc. Cell Biol. 2021, 25 (6), 1096-1106.

(46) Kumara, P. A Study Of The Relationship Between Occupational Stress And Emotional Intelligence Of Degree College Teachers. Turk. J. Comput. Math. Educ. TURCOMAT 2021, 12 (3), 3490-3493.

(47) Martínez-Monteagudo, M. C.; Inglés, C. J.; Granados, L.; Aparisi, D.; García-Fernández, J. M. Trait Emotional Intelligence Profiles, Burnout, Anxiety, Depression, and Stress in Secondary Education Teachers. Personal. Individ. Differ. 2019, $142,53-61$.

(48) Leonova, I. M.; Yevchenko, I. M.; Masliuk, A. M.; Brahina, K. I.; Salata, H. V. Emotional Intelligence as a Factor against Burnout in Female Students and Teachers. J. Intellect. Disabil.-Diagn. Treat. 2021, 9 (3), 280-293.

(49) Schoeps, K.; Tamarit, A.; Peris-Hernández, M.; Montoya-Castilla, I. Impact of Emotional Intelligence on Burnout among Spanish Teachers: A Mediation Study. Psicol. Educ. Rev. Los Psicólogos Educ. 2021, 27 (2), 135-143.

(50) Mérida-López, S.; Extremera, N. Emotional Intelligence and Teacher Burnout: A Systematic Review. Int. J. Educ. Res. 2017, 85, 121-130.

(51) Karakuş, M. Emotional Intelligence and Negative Feelings: A Gender Specific Moderated Mediation Model. Educ. Stud. 2013, $39(1), 68-82$.

(52) Chișa, A.; Rusua, A. S. Connecting Emotional Intelligence and Academic Achievement in Adolescence: A Systematic Review. BE-Ci 2016, 2016, 3rd.

(53) Alam, A.; Ahmad, M. The Role of Teachers' Emotional Intelligence in Enhancing Student Achievement. J. Asia Bus. Stud. 2018, 66-79.

(54) Curci, A.; Lanciano, T.; Soleti, E. Emotions in the Classroom: The Role of Teachers' Emotional Intelligence Ability in Predicting Students' Achievement. Am. J. Psychol. 2014, 127 (4), 431-445.

(55) Pishghadam, R.; Sahebjam, S. Personality and Emotional Intelligence in Teacher Burnout. Span. J. Psychol. 2012, 15 (1), 227236.

(56) Kolb, A. Y.; Kolb, D. A.; Passarelli, A.; Sharma, G. On Becoming an Experiential Educator: The Educator Role Profile. Simul. Gaming 2014, 45 (2), 204-234.

(57) Grasha, A. F. A Matter of Style: The Teacher as Expert, Formal Authority, Personal Model, Facilitator, and Delegator. Coll. Teach. 1994, 42 (4), 142-149.

(58) Garvis, S.; Twigg, D.; Pendergast, D. Breaking the Negative Cycle: The Formation of Self-Efficacy Beliefs in the Arts. A Focus on Professional Experience in Pre-Service Teacher Education. Australas. J. Early Child. 2011, 36 (2), 36-41.

(59) Albuquerque, A.; Sa, P.; Aranha, A.; Resende, R. Teacher Profile: The Knowledge and the Identity Practices. Open Sports Sci. J. 2014, 7 (1), 66-78.

(60) Ghanizadeh, A.; Jahedizadeh, S. EFL Teachers' Teaching Style, Creativity, and Burnout: A Path Analysis Approach. Cogent Educ. 2016, 3 (1), 1151997.

(61) Akbari, R.; Tavassoli, K. Teacher Efficacy, Burnout, Teaching Style, and Emotional Intelligence: Possible Relationships and Differences. 2011.

(62) Hosseini Fatemi, A.; Raoufi, R. Burnout and Teaching Style among Iranian English Language Educators in Public Schools and Private Institutes: A Cross-Comparison Study. Int. J. Res. Stud. Lang. Learn. 2014, 17.

(63) Tikkanen, L.; Pyhältö, K.; Pietarinen, J.; Soini, T. Interrelations between Principals' Risk of Burnout Profiles and Proactive SelfRegulation Strategies. Soc. Psychol. Educ. 2017, 20 (2), 259-274.

(64) Fernández-Batanero, J.-M.; Román-Graván, P.; Reyes-Rebollo, M.-M.; Montenegro-Rueda, M. Impact of Educational Technology on Teacher Stress and Anxiety: A Literature Review. Int. J. Environ. Res. Public. Health 2021, 18 (2), 548.

(65) Wang, X.; Li, B. Technostress among University Teachers in Higher Education: A Study Using Multidimensional PersonEnvironment Misfit Theory. Front. Psychol. 2019, 10, 1791.

(66) Othman, Z.; Sivasubramaniam, V. Depression, Anxiety, and Stress among Secondary School Teachers in Klang, Malaysia. Int. Med. J. 2019, 26 (2), 71-74.

(67) OECD Give Teachers a Say: Facing the Challenge of Teachers' Work-Related Stress in the COVID-19 Crisis; Teaching in Focus 36; 2020; Vol. 36. https://doi.org/10.1787/05da3183-en.

(68) Hämäläinen, R.; Nissinen, K.; Mannonen, J.; Lämsä, J.; Leino, K.; Taajamo, M. Understanding Teaching Professionals’ Digital Competence: What Do PIAAC and TALIS Reveal about Technology-Related Skills, Attitudes, and Knowledge? Comput. Hum. Behav. 2021, 117, 106672. 
(69) Lucas, M.; Bem-Haja, P.; Siddiq, F.; Moreira, A.; Redecker, C. The Relation between In-Service Teachers' Digital Competence and Personal and Contextual Factors: What Matters Most? Comput. Educ. 2021, 160, 104052.

(70) Mäkikangas, A.; Kinnunen, U. The Person-Oriented Approach to Burnout: A Systematic Review. Burn. Res. 2016, 3 (1), 11-23.

(71) Ferradás, M. del M.; Freire, C.; García-Bértoa, A.; Núñez, J. C.; Rodríguez, S. Teacher Profiles of Psychological Capital and Their Relationship with Burnout. Sustainability 2019, 11 (18), 5096.

(72) Salmela-Aro, K.; Hietajärvi, L.; Lonka, K. Work Burnout and Engagement Profiles among Teachers. Front. Psychol. 2019, 10, 2254.

(73) Mojsa-Kaja, J.; Golonka, K.; Marek, T. Job Burnout and Engagement among Teachers: Worklife Areas and Personality Traits as Predictors of Relationships with Work. Int. J. Occup. Med. Environ. Health 2015, 28 (1).

(74) Ballantyne, J.; Retell, J. Teaching Careers: Exploring Links between Well-Being, Burnout, Self-Efficacy and Praxis Shock. Front. Psychol. 2020, 10, 2255.

(75) Bakioğlu, F.; Kiraz, Z. Burnout and Wellbeing of Teacher Candidates: The Mediator Role of Cynicism. An. Psicol. Psychol. 2019, 35 (3), 521-528.

(76) Petrides, K. V. Psychometric Properties of the Trait Emotional Intelligence Questionnaire (TEIQue). In Assessing Emotional Intelligence; Parker, J. D. A., Saklofske, D. H., Stough, C., Eds.; The Springer Series on Human Exceptionality; Springer US: Boston, MA, 2009; pp 85-101. https://doi.org/10.1007/978-0-387-88370-0_5.

(77) Kent, P.; Jensen, R. K.; Kongsted, A. A Comparison of Three Clustering Methods for Finding Subgroups in MRI, SMS or Clinical Data: SPSS TwoStep Cluster Analysis, Latent Gold and SNOB. BMC Med. Res. Methodol. 2014, 14 (1), 1-14.

(78) Nunnally, J. C. The Assessment of Reliability. Psychom. Theory 1994.

(79) West, S. G.; Finch, J. F.; Curran, P. J. Structural Equation Models with Nonnormal Variables: Problems and Remedies. 1995.

(80) Agustino, R.; Pertiwi, S. Estimation of the Relationship Between Learning Styles Inventory and Online Learning During the Pandemic; 2020; Vol. 3, pp 553-561.

(81) Syahrin, S.; Salih, A. A. An ESL Online Classroom Experience in Oman during Covid-19. Arab World Engl. J. 2020, 11 (3), $42-$ 55.

(82) Rahayu, R. P.; Wirza, Y. Teachers' Perception of Online Learning during Pandemic Covid-19. J. Penelit. Pendidik. 2020, 20 (3), 392-406.

(83) Pozo-Rico, T.; Gilar-Corbí, R.; Izquierdo, A.; Castejón, J.-L. Teacher Training Can Make a Difference: Tools to Overcome the Impact of COVID-19 on Primary Schools. An Experimental Study. Int. J. Environ. Res. Public. Health 2020, 17 (22). https://doi.org/10.3390/ijerph17228633. 